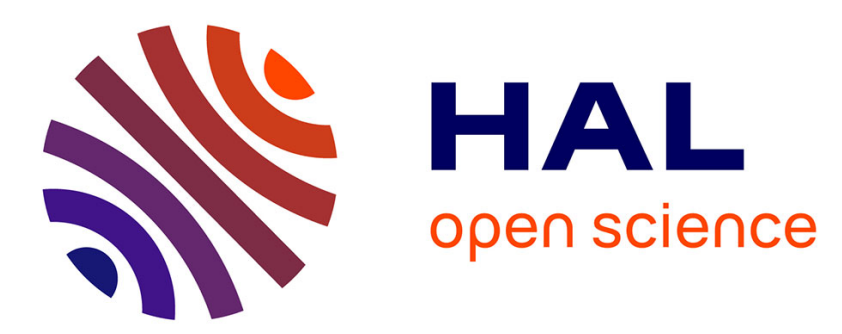

\title{
Raman identification of glassy silicates used in ceramics, glass and jewellery: a tentative differentiation guide
}

\author{
Philippe Colomban, Aurélie Tournié, Ludovic Bellot-Gurlet
}

\section{To cite this version:}

Philippe Colomban, Aurélie Tournié, Ludovic Bellot-Gurlet. Raman identification of glassy silicates used in ceramics, glass and jewellery: a tentative differentiation guide. Journal of Raman Spectroscopy, 2006, 37, pp.841-852. hal-00120401

\section{HAL Id: hal-00120401 https://hal.science/hal-00120401}

Submitted on 14 Dec 2006

HAL is a multi-disciplinary open access archive for the deposit and dissemination of scientific research documents, whether they are published or not. The documents may come from teaching and research institutions in France or abroad, or from public or private research centers.
L'archive ouverte pluridisciplinaire HAL, est destinée au dépôt et à la diffusion de documents scientifiques de niveau recherche, publiés ou non, émanant des établissements d'enseignement et de recherche français ou étrangers, des laboratoires publics ou privés. 
Six years of experience on various materials has enabled us to propose a tentative guide to recognize different types of glassy silicates and to classify them as a function of their composition. Raman parameters extracted from spectra are processed using also multivariate analysis (cluster and PCA). An illustration of the method is presented by differentiating between Iznik and Kütaya productions.

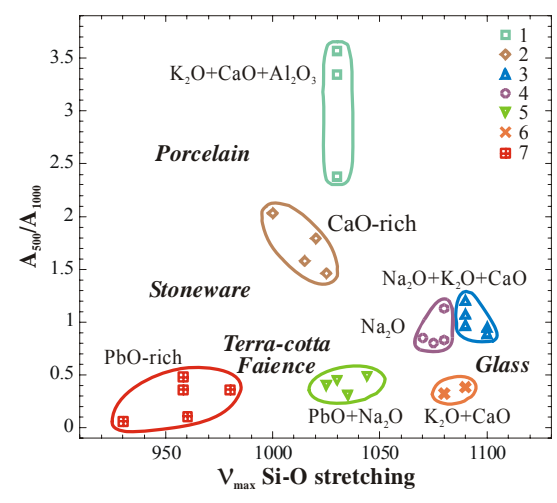

$\mathrm{Ph}$. Colomban, Aurélie Tournié and Ludovic Bellot-Gurlet

Raman identification of glassy silicates used in ceramic, glass and jewellery: a tentative differentiation guide 


\title{
Raman identification of glassy silicates used in ceramics, glass and jewellery: a tentative differentiation guide
}

\author{
Philippe COLOMBAN*, Aurélie TOURNIE, Ludovic BELLOT-GURLET \\ Laboratoire Dynamique, Interactions et Réactivité UMR 7075 CNRS \& UPMC \\ 2 rue Henry Dunant, 94320 THIAIS, France \\ *fax 33149781118 \\ colomban@glvt-cnrs.fr
}

\begin{abstract}
As an optical method, Raman (micro)-spectroscopy offers a great advantage over most other techniques in that it can be performed without any contact with the studied artefact, both at the laboratory using high-resolution, large spectral window instruments, as well as on-site using medium resolution, portable instruments. Six years of experience on various materials has enabled us to propose a tentative guide to identify different types of glassy silicates and to classify them as a function of their composition. In previous papers different families were recognized empirically using a limited set of samples and the relationship between the peak area ratio $\left(A_{500} / A_{1000}\right)$ of the Si-O bending $\left(-500 \mathrm{~cm}^{-1}\right)$ and stretching (i.e. $\sim 1000 \mathrm{~cm}^{-}$ $\left.{ }^{1}\right)$ envelopes and the different components of the latter peak were established for porcelain glazes. In this paper we extend the procedure to a larger set of samples (30 representative samples with known compositions selected from hundreds of spectra). Additional relationships between the origin of the material, the Raman parameters and the glass composition (fluxing oxide content, ionicity ratio,...) are discussed. Finally we propose different procedures, with different degrees of complexity (from two to multivariate treatment), to identify the glass composition. The method is illustrated with an example, namely the differentiation between Iznik and Kütahya productions.
\end{abstract}

Keywords : Raman, glass, glaze, silicate, composition, assignment, guide 


\section{INTRODUCTION}

Leading experts generally base their certification of ancient artefacts on stylistic analysis and on personal sensory perceptions. However, greater objectivity is mandatory for identification, dating and conservation purposes. We have previously demonstrated the potential of Raman spectroscopy as a non-destructive on-site technique [1-4]. Salient features can thus be extracted from bodies, glazes/enamels and pigments from different productions covering the history of the ceramic and glass industries. Six years of experience on various artefacts (Phoenician, Roman, Islamic, Medieval and modern glass, Asian, European and Islamic faience, fritware, stoneware and porcelain, etc. $[5,6])$ has enabled us to propose a tentative guide to recognize the different types of glassy silicates and to classify them as a function of their composition. In previous papers [1,7] different families were identified empirically and we established the relationship between the Raman parameters (peak area ratio $\left(\mathrm{A}_{500} / \mathrm{A}_{1000}\right)$ of the Si-O stretching (i.e.. $\left.\sim 1000 \mathrm{~cm}^{-1}\right)$ and bending $\left(\sim 500 \mathrm{~cm}^{-1}\right)$ envelopes, wavenumbers of the different Si-O stretching components,...). A first test of the "quantitative" validity of this description was made for a series of high-temperature fired porcelain glazes [8]. In this paper we will test the procedure for a larger set of samples, covering most of the glassy silicates used in ancient ceramic and glass production.

The $\mathrm{SiO}_{4}$ tetrahedron, the building block of all silicates, amorphous or crystalline, is a very covalent entity and thus has a well-defined vibrational signature, especially in Raman scattering. The latter technique is more convenient than IR analysis because the experimental procedure does not require sample preparation and Raman peaks are usually less broad than those of its IR counterpart. Pure amorphous silica can be described as a 3D network of $\mathrm{SiO}_{4}$ tetrahedra sharing their oxygen atoms and forming Si-O-Si bridges. Consequently the density of Si-O bonds is at its maximum and melting (i.e. the softening of the $3 \mathrm{D}$ connected $\mathrm{Si}-\mathrm{O}$ network) requires high temperatures $\left(\sim 1750^{\circ} \mathrm{C}\right)$. All applications in the science, art and technology of glass, glazes and enamels consist out of a controlled modification of the 3D Si-O network by replacement of $\mathrm{Si}^{4+}$ covalent bonded atoms by non-covalent bonded atoms, hence decreasing the number of Si-O bridges and the connectivity of the network. Consequently, the melting temperature (and the viscosity at a given temperature) decreases. Other physical/chemical properties related to the density and network connectivity (thermal expansion, ion diffusion, reactivity, etc.) are modified accordingly. Direct relationships between the silica content, or more precisely the ratio between the glass-former (chiefly Si and Al oxides) and the flux (Na, K, Ca, Pb oxides) content and the properties of glassy silicate have been established for a long time (Seeger's rules and modern developments by Stevels, Huggins, etc [912]). Because strong covalent bonded structures have Raman signatures orders of magnitude larger than those of ionic ones, the Raman spectrum of a silicate consists, as a first approximation, solely out of the signature of the Si-O network (Si-O stretching, bending and librational/collective modes) [1]. Because a $\mathrm{SiO}_{4}$ tetrahedron is a solid chemical and vibrational entity (molten silicates retain a strong polymeric character), it is well established that the different tetrahedral arrangements (see the schematic diagram in Fig. 1a): isolated tetrahedra referred to as $\mathrm{Q}_{0}$, tetrahedra linked by a common oxygen atom $\left(\mathrm{Si}_{2} \mathrm{O}_{7}\right.$ or $\left.\mathrm{Q}_{1}\right)$, tetrahedra linked by sharing 2 oxygen atoms (three $\left(\mathrm{Si}_{3} \mathrm{O}_{9}\right)$ and $\mathrm{n}$ tetrahedral-cycles: $\mathrm{Q}_{2}$ ), by sharing 3 oxygen atoms (e.g. in some chains, ribbons and layers) and $\mathrm{Q}_{4}$ (as in pure $\mathrm{SiO}_{2}$ ) have characteristic Raman signatures $[1,7,8,13,14]$. An example of $\mathrm{Q}_{\mathrm{n}}$ decomposition is given in Fig. 1b. Glaze spectra generally exhibit additional narrow Raman peaks due to pigments or crystalline precipitates [5,6]. These signatures must be identified and not considered in the analysis of the glassy silicate signature. Note that this molecular description 
considers only the main components (e.g. the anti-symmetric stretching mode is neglected) and its validity in the description of the Si-O "bending" massif (near $400-500 \mathrm{~cm}^{-1}$ ) is more problematic. In fact the substitution of $\mathrm{Si}$ atoms by $\mathrm{Na}, \mathrm{K}, \mathrm{Ca}, \mathrm{Pb}$ ones does not only change the connectivity (and $\mathrm{Si}-\mathrm{O}$ angles) but also the partial ionic charge of terminal oxygen atoms, which modify bond length and polarizability and hence the Raman "cross section" of the different modes. However, the spectrum of a silica-rich hard-paste glaze consists of a strong band at $\sim 500 \mathrm{~cm}^{-1}$ (Si-O bending massif) and a weak bump at $\sim 1000 \mathrm{~cm}^{-1}$ (Si-O stretching modes). On the contrary the $1000 \mathrm{~cm}^{-1}$ massif dominates the spectrum of a PbO-rich glaze. Glasses and glazes with intermediate $\left[0.5 \mathrm{Na}_{2} \mathrm{O}\right.$ $\left.+0.5 \mathrm{~K}_{2} \mathrm{O}+\mathrm{CaO}+\mathrm{PbO}+\ldots\right] /\left[\mathrm{SiO}_{2}+\mathrm{Al}_{2} \mathrm{O}_{3}\right]$ (flux/network former) ratios have intermediate Raman signatures [7]. The polymerisation index $I_{P}$ is defined as $I_{P}=A_{500} / A_{1000}$ with $A$ being the area under the Raman band [7]. The empirical relationship between $\mathrm{I}_{\mathrm{p}}$, the glass composition and the processing temperature is rather well documented [7,8]: a first family $\left(\mathrm{I}_{\mathrm{p}}<0.3-0.5\right)$ mostly corresponds to leadrich silicates processed at low temperatures $\left(<700^{\circ} \mathrm{C}\right)$; a second family $\left(0.5<\mathrm{I}_{\mathrm{p}}<0.8\right)$ consists of some lead-based silicates processed at medium temperature $\left(800^{\circ} \mathrm{C}\right)$; a third family $\left(0.8<\mathrm{I}_{\mathrm{p}}<1.1\right)$ corresponds to most ancient alkaline glasses and enamels; family $4\left(1.1<\mathrm{I}_{\mathrm{p}}<1.3\right)$ and family $5(1.3$ $\left.<\mathrm{I}_{\mathrm{p}}<2.5\right)$ to Ca-based glassy silicates. Family $6\left(2.5<\mathrm{I}_{\mathrm{p}}\right)$ corresponds to K-based glazes. $\mathrm{I}_{\mathrm{p}}$ is strongly correlated to the processing temperature $\left(\sim 1400^{\circ} \mathrm{C}\right.$ for $\mathrm{I}_{\mathrm{p}} \sim 7,1000^{\circ} \mathrm{C}$ for $\mathrm{I}_{\mathrm{p}} \sim 1$ and $\sim 600^{\circ} \mathrm{C}$ or less for $\left.\mathrm{I}_{\mathrm{p}} \sim 0.3\right)$. The polymerisation index concept is now used by different groups $[15,16]$.

In this paper we will verify the relationship between the composition of glassy silicates and the parameters of their Raman signatures (centre of gravity and area of the $\mathrm{Q}_{\mathrm{n}} \mathrm{Si}-\mathrm{O}$ components and polymerisation index) for a large set of samples and propose an atlas of the Raman signatures' characteristics of the various types of glassy silicates.

\section{ESTABLISHMENT OF THE DATA BASE}

During the last six years we have analysed a large number of glassy materials, collected and fitted more than 700 Raman spectra. The materials studied are glass, porcelain, stoneware, terra cotta and faience glaze [1-8,17-28]. Among these we selected 30 representative spectra (Tables 1 and 2). Fig. 2 shows that the corresponding values of their index of polymerisation cover a large range, from $\sim 0.2$ to $\sim 5$. Among these 30 materials the composition of 22 glassy silicates was determined by ourselves, using various methods (Table 1) or we are confident in the accuracy of the compositions determined by other groups. For instance, for the Iznik glazes (our composition analysis concern only some elements), we used compositions obtained by other groups for very similar materials [30]. We selected Raman signatures of glazes in which the contribution of pigments and precipitate crystalline phases is small or nil. In Fig. 3 we have labelled the flux and the corresponding wt \% content of $\mathrm{Na}_{2} \mathrm{O}, \mathrm{K}_{2} \mathrm{O}, \mathrm{CaO}$ and $\mathrm{PbO}$. It is obvious that there is a relationship between the Raman index of polymerisation and the nature and content of the fluxing cation : note the decreasing values of flux content from left to right, i.e. from low temperature (PbO-rich glass and glaze) to high temperature melting compositions (porcelain glaze) as previously established $[7,8]$.

\section{PEAK FITTING AND PARAMETER EXTRACTION}

In undertaking a curve fit of the Raman spectra, a 4-segment linear baseline ( 100-700, 700-800, $\sim 800-1300$ and $>1300 \mathrm{~cm}^{-1}$ ) was first subtracted using Labspec (Dilor) software. The number of reference points was minimal, from 4 to 8 , and kept constant for attaching the baseline segment to 
the different spectra. This type of baseline subtraction make it possible to retain only the "molecular" Si-O Raman signature and to eliminate the so-called "Boson peak" contribution, which is very large for $\mathrm{PbO}$-rich glasses because the heavy $\mathrm{Pb}$ atoms modify the phonon propagation and activate other types of modes giving a "density of state" spectrum, arising from the projection of the dispersion curves of the Brillouin zone. Representative examples are presented in Fig. 4. Our experience led us to consider this type of baseline subtraction as the best way to compare spectra of samples with various compositions. Obviously, the procedure remains partly subjective. A Gaussian shape was assumed for the Raman lines of the glassy silicate network because of the amorphous state of the examined materials; a Lorentzian shape is used for narrow bands related to crystalline moieties. The same spectral windows were used for the extraction of the components using the Origin software peak-fitting module (Microcal Software, Inc.).

A plot of the polymerisation index as a function of the $Q_{n}$ wavenumber (Fig. 6) makes it possible to monitor the validity of the description according our molecular model: Ip and $v Q_{n}$ increase together because the strength of the Si-O bond increases with polymerisation. A gap may remain between $\mathrm{Q}_{\mathrm{n}}$ and $\mathrm{Q}_{\mathrm{n}+1}$ groups, which will decrease with polymerisation: the difference between $\mathrm{Q}_{4}$ and $\mathrm{Q}_{3}$ is less than between $\mathrm{Q}_{3}$ and $\mathrm{Q}_{2}$, less than ..., and so forth. $\mathrm{Q}_{\mathrm{n}}$ wavenumber increases with Ip because the structure becomes more compact and strongly bonded. The relationship between Ip and $\mathrm{Q}_{\mathrm{n}}$ wavenumber reflects a regular curve, except for $\mathrm{Q}_{2}$ wavenumber which shows two groups of data. Note, that in spite of the rather limited range of variation $\left(740-800 \mathrm{~cm}^{-1}\right), \mathrm{Q}_{0}$ wavenumbers follow a rather well defined polynomial curve. This indicates that $\mathrm{Q}_{0}$ wavenumber is very sensitive to the modification of the glass structure.

In Figure 5 the spectra shown in Fig. 4 have been fitted according to the procedure. The integral area under each component of the envelope was calculated. The following assumptions were made: i) for the Si-O stretching range extending from 700 to $1300 \mathrm{~cm}^{-1}$ we postulated 5 (or less) components assigned to $\mathrm{Q}_{0}, \mathrm{Q}_{1}, \mathrm{Q}_{2}, \mathrm{Q}_{3}$ and $\mathrm{Q}_{4}$ ii) we also postulated 5 bands or less with similar bandwidths for the Si-O bending range. $[1,7,8]$. The results are summarized in Table 2. Note that the $\mathrm{Q}_{\mathrm{n}}$ component wavenumber and area ratio are representative signatures of the different productions $[6,23]$.

\section{THE FAMILIES}

As previously empirically established [7] and tested for a limited range of samples [8], there is a good relationship between Raman parameters and compositional parameters. The study of porcelain glazes [8] evidenced a good correlation between polymerisation index and the area under the $\mathrm{Q}_{2}$ component with two important composition parameters, the $\mathrm{Al} / \mathrm{Si}\left(\left[0.5 \mathrm{Al}_{2} \mathrm{O}_{3} / \mathrm{SiO}_{2}\right]\right.$ mole ratio) and $\mathrm{M} / \mathrm{Al}+\mathrm{Si}\left(\left[0.5 \mathrm{Na}_{2} \mathrm{O}+0.5 \mathrm{~K}_{2} \mathrm{O}+\mathrm{CaO}\right] /\left[0.5 \mathrm{Al}_{2} \mathrm{O}_{3} / \mathrm{SiO}_{2}\right]\right.$ mole ratio) ratio. From previously published compositions [17-19, 30-37], we plotted the above parameters for a series of samples (Fig. 7). Classification of the different types is obvious. Note that our Raman data processing method would be more efficient for groups exhibiting a non-constant behaviour, for instance Islamic glasses and glazes. Plateau behaviour indicates that the compositional changes are small and certainly other criteria (for example, trace content) would be more useful for a classification as a function of the production date and place.

In previous papers $[7,8]$ we established 6 families. In this previous semi-quantitative examination, the main criteria were the band intensity and the peak "shape" (wavenumber of the maximum and of its principal shoulder). According to our hypothesis that the Raman signature is determined by the polymerisation degree of the silicate network, the different families can be associated with the main fluxing agent or to an association of such a cation. Fig. 8 shows that within a family the Raman 
signatures are very similar. Confirmation is given by calculation of the mean Ip value (Table 2). The additional family "6" in Figs 4 \& 5 and Table 2) corresponds to modern glass used to replace ancient stained glass and to some modern celadon glazes.

In order to check the validity of our classification, we plotted the polymerisation index as a function of the position of main Si-O stretching component wavenumber in Fig. 9a (i.e. the peak maximum wavenumber). Classification is evident,

- from the top to the bottom as a function of the melting/processing temperature : at the top porcelain and then stoneware glazes, below, faience and terra-cotta glazes and glasses, all types of low temperature processed silicates.

- from the left to the right as function of the main flux.

The separation between the families is rather good. Of course some separation are more subjective, especially for glass, but the position can be correlated to the main fluxing element $(\mathrm{Na}, \mathrm{K}, \mathrm{Ca}$ or $\mathrm{Pb}$ ). Fig. $9 \mathrm{~b}$ plots the polymerisation index as a function of the $\mathrm{Q}_{2} / \mathrm{Q}_{1}$ component area ratio. From our previous studies $[6,7,23]$ the $\mathrm{AQ}_{2} / \mathrm{AQ}_{1}$ ratio can be used to classify different glazes. Families 1 and 2 form well defined and isolated groups. Families 3 and 4 can be differentiated as a function of the $\mathrm{AQ}_{2} / \mathrm{AQ}_{1}$ area ratio, not from the Ip value. Family 6 intersect Families 7 and 3/4. Note that Ip and $v_{\max }$ parameters can be determined without any peak fitting procedure, using very simple procedures.

As a preliminary conclusion, it is evident that the composition type of any glassy silicate can be associated to a specific Raman signature, but the more pertinent parameter for a classification changes with the considered set of samples. In a first approach Ip and the peak maximum wavenumber of the Si-O stretching envelope are good tools. However in this work we don't consider all the information available in the Raman spectrum. For instance, it was established that the broad band at $\sim 500 \mathrm{~cm}^{-1}$, assigned to the bending $\mathrm{Si}-\mathrm{O}$ mode using a $\mathrm{SiO}_{4}$ vibrational model is sensitive to the variation of the Si-O-Si angle $[38,39]$ and for this reason very sensitive to change of the cation size and charge which modify this angle for geometric and electric reasons. Consequently, ion exchange by protonic entities strongly shifts the wavenumber towards lower values [39].

\section{MULTIVARIATE DATA ANALYSES}

In order to expand our understanding of the criteria of classification and the relationship between the different parameters that can be extracted from a Raman signature and to establish a reproducible and simple procedure, we "processed" our data (the parameters extracted from the Raman signatures, Table 2) with two multivariate techniques of data analysis, the Cluster Analysis (CA) and the Principal Component Analysis (PCA). These methods are available from various home made and commercial software, in this study we use the Statistica 6.1 (Statsoft) package. In order to prevent some "size" effect due to variables means and dispersions heterogeneity data set is first centred and standardised (normalised in order to obtain a mean value set at zero and a standard deviation at one). In Cluster Analysis distances between each samples are calculated in the parameter hyperspace [40]. Then a hierarchical tree diagram assembles samples as a function of the shortest distance. Clusters presented are built using an Euclidean distance and the amalgamation rule selected is the Ward's method.

In Principal Component Analysis, new "axes" called Principal Components (PC) are calculated by forming linear combinations of the original variables [40,41]. The first PC is calculated in order to contains the maximum variance from the data set, the second the next highest amount, and so forth. 
These new, orthogonal, axes are used to illustrate the parameters distribution structure. On the other hand, the projection of the initial parameters on the PC emphasises the contribution of each variable in sample discrimination.

These methods of classification has been for a long time to classify stones, ceramics and glasses from their elemental composition, including trace elements [18,42-45]. Recently the technique was extended to spectroscopic, IR and Raman parameters extracted from the spectra [46,47].

The hierarchical cluster built with 10 parameters, Ip, the Si-O stretching peak maximum and the peak areas and positions of the $\mathrm{Q}_{0}, \mathrm{Q}_{1}, \mathrm{Q}_{2}$ and $\mathrm{Q}_{3}$ components is shown in Fig. 10. The three major groups identified are composed by the families: $1+2+3,3+4+5+6$ and 7 . Obviously the increase of the number of the parameters do not lead to the clear-cut picture of Fig. 9a. The first group corresponds to porcelain glazes $(1+2+$ some data of 3$)$. Family 7 , consists of lead-rich glazes, remains isolated. The third group contains families $4+6$, some data of family 3 and family 5 . However, the latter family appears in a single sub-branch.

To refine the selection of the most discriminating parameters, a Principal Component Analysis is performed for the 30 spectra and their 10 parameters (Ip, Si-O stretching peak maximum, $Q_{n}$ wavenumbers and peak area). To illustrate parameters behaviour Fig. 11 present the projection of variables on the two first principal component (factor).

On the other hand, the projection of the initial parameters on the PC emphasises the contribution of each variable in sample discrimination. In this representation the projections of rather "independent" parameters are perpendicular. On the contrary, the parameters which have projections in the same direction, get a rather similar behaviour. Thus it can be expected from parameters close to be perpendicular to be more informative for sample discrimination.

For instance, Ip, the Si-O stretching peak maximum wavenumber and some area $\left(\mathrm{AQ}_{\mathrm{n}}\right)$ appear to be a good choice for a first classification. Some peak areas and even the $\mathrm{Q}_{\mathrm{o}}$ wavenumber are other informative parameters. Note that the plot of the polymerisation index versus $Q_{n}$ wavenumbers (Fig. 6 ) already pointed out some correlation, with a larger variation versus $Q_{0}$ wavenumber in spite of the rather small range of variation the wavenumber.

\section{CASE STUDY: DISCRIMINATION BETWEEN IZNIK AND KÜTAHYA GLAZES}

In our previous work we drew a comparison between the Raman signatures of Ottoman Iznik and Kütahya productions $[4,23]$. At least two types of Si-O stretching signatures have been observed for Kütahya ceramic glazes, in contrast the Raman signature of the Iznik productions does not vary very much between centuries of production. This very special behaviour was related to the very efficient control made by the "Ottoman office for fine art" (nakkashane). Large fluctuations are noted for Kütahya ones. However, in some instances a rather similar signature can be obtained for both types (or for artefacts assigned to) of factories. Fig. 12a shows the location of the data extracted from the Raman spectra of Iznik and Kütahya glazes in the bi-plot of Fig. 9a where Ip is plotted as a function of the Si-O stretching peak maximum. Most of the Kütayha glazes can be associated to family 7 (PbO-rich glass) but some of them are located in the Iznik group (see the measurement for the 7460 sample, a small dish with depicted personage). On the other hand Iznik glazes are all located in between family $5\left(\mathrm{Na}_{2} \mathrm{O}+\mathrm{PbO}\right)$ and family $4\left(\mathrm{Na}_{2} \mathrm{O}\right.$-rich silicates) except for two types of glazes, the red Armenian bole (located in the family 7 area) and the dark green glaze (located in the $\mathrm{CaO}$ - 
rich family 2). The red bole is the last one glaze to be applied in the décor and it requires a lower temperature of processing, and hence more $\mathrm{PbO}$ in its composition. The dark green glaze is made with a Cr-containing pigment which develop the nice green color by forming uranovite-type garnet, a calcium silicate. The two parameters, Ip and $v_{\max }$, appear good tools for the classification.

Rather similar information can be obtained from multivariate cluster analysis. In Fig. 12b we present the hierarchical tree calculated using 10 parameters for the Iznik and Kütahya series. Classification of the different Iznik and Kütahya assigned productions is obvious, except for a Kütahya sample MNC7460, incorporated in the Iznik group. This questions the assignment and/or give information on the technology relationship between two factories and deserves further study using this procedure.

\section{CONCLUSION}

The consideration of a rather large set of glazes and glasses representative of different types, covering a time span from the origin of the glass and ceramic industry to modern times, for which both Raman spectra and accurate compositional analyses were available, enabled us to confirm unambiguously the validity of our empiric description. The use of two parameters, namely the Si-O stretching peak maximum and the polymerisation index, is sufficient to classify the glassy silicates as a function of their composition types, according to the seven families recognized. The use of more criteria lead to 4 groups. Cluster and principal component analysis from main parameters, derived from their Raman signatures appear to be a good method to classify glasses and glazes belonging to a limited range of the above classification. These results deserve further studies to discriminate between sets of artefacts where the origin of production and date are under investigation.

\section{ACKNOWLEGMENTS}

The authors would like to thanks Mr. G. Sagon for his collaboration in the artefact analysis and Mrs V. Milande, L. Soustiel and M.C. David and Mr. Ph. Magloire for their help in selecting the artefacts. Special thanks to Dr B. Lenain, Kayser Optical Sarl, Lyon and to Dr. J. Oswalt, JobinYvon SAS, Longjumeau providing their portable spectrometers and to Mrs L. Prinsloo for the critical reading of the manuscript.

\section{REFERENCES}

1. Colomban Ph, Treppoz F. J. Raman Spectr. 2001; 32: 93.

2. Colomban Ph, Sagon G, Faurel X. J. Raman Spectrosc. 2001; 32: 351.

3. Colomban Ph, Milande V, Lucas H, J. Raman Spectr. 2004; 35: 68.

4. Colomban Ph., Milande V., Le Bihan L., J. Raman Spectr. 2004; 35:527.

5. Colomban Ph, Glasses, Glazes and Ceramics - Recognition of the Ancient Technology from the Raman Spectra, chapter in Raman Spectroscopy in Archaeology and Art History, Edwards HGM and Chalmers JM (Eds), Royal Society of Chemistry, London, 2005, ch. 13, pp 192-206.

6. Colomban Ph, Mater. Res. Soc. Proc. vol 852E

7. Colomban Ph. J. Non-Crystalline Solids, 2003; 322: 180. 
8. Colomban Ph., Paulsen O., J. Amer. Ceram. Soc. 2005; 88: 390.

9. Stevels J.M., Pilips Techn. Rev., 1960-1961; 22: 300.

10. Huggins M.L., Sun K.H., J. Amer. Ceram. Soc, 1943; $26: 4$.

11. Volf M.B., Technical Glasses, Pitman, London, 1961.

12. Pollard A.M., Heron C., Archaeological Chemistry, RSC Paperbacks, Cambridge,1996, ch. 5, pp149-195.

13. Mysen BO, Virgo D, Scarfe C. Am. Mineral. 1980; 65: 690.

14. Seifert F, Mysen BO, Virgo D. Am. Mineral. 1982; 67: 696.

15. L.C. Prinsloo, N. Wood, M. Loubser, S. M. C. Verryn, S. Tiley, J. Raman Spectrosc. 2005; 36: 808.

16. Ollier N., Charpentier T., Boizot B., Wallez G. , D. Ghaleb, J. Non-Crystall. Solids 2004; 341: 26.

17. Colomban Ph. Truong C., J. Raman Spectrosc. 2004; 35: 195.

18. Colomban Ph, March G, Mazerolles L, Karmous T, Ayed N, Ennabli A, Slim H. J. Raman Spectrosc., 2003; 34: 205.

19. Liem NQ, Colomban Ph, Sagon G, Tinh HX, Hoang TB, J. Cult. Heritage 2003; 4: 187.

20. Liem NQ, Thanh NT, Colomban Ph, J. Raman Spectrosc. 2002; 33: 287.

21. Colomban Ph, Sagon G, Louhichi A, Binous, H, Ayed N. Revue Archéométrie 2002; 25: 101.

22. Colomban Ph., Schreiber H.G., J. Raman Spectrosc. 2005; 36:.

23. Co lomban Ph., de Laveaucoupet R., Milande V., J. Raman Spectrosc. 2005; 36:.

24. Colomban Ph., Calligaro Th., Vibert-Guigue Cl., Liem N.Q., Edwards H.G.M., Revue Archéométrie 2005; 29

25. Bellot-Gurlet L., PhD Thesis, Université Joseph Fourier-Grenoble I, 1998, pp. 290.

26. Edwards H.G.M., Colomban Ph., Bowden B., J. Raman Spectrosc. 2004; 35: 656.

27. Colomban Ph., Asquier M., Tournié A., Etscheverry M.P., to be published.

28. Caner-Saltik E.N., Colomban Ph., Demirci S., Tükmenog glu A., Özcilingir-Akgün S., Bakirer Ö., Proc. Archéometrie 2003, 16-19 april 2003, Bordeaux, p.

29. Henderson J, ch VI, in Atasoy N, Raby J in Iznik, The pottery of Ottoman Turkey, Petsopoulos Y Ed., Alexandria Press, London, 1989, p. 65.

30. Fukang Z., The Origin of High fired glazes in China, in Scientific and Technological Insights on Ancient Chinese Pottery and Porcelain International Conference, Ed. Shanghai Institute of Ceramics, 1986, 65-83.

31. Freestone I.C. , Stapleton C.P., Composition and technology of Islamic enameled glass, in Gilded an Enamelled Glass from MiddleEast, Ed. R. Ward, British Museum Press, 1998, 122-128.

32. Mass L., StoneR.E., Wypiski M.T., The mineralogical and metallurgical origins of Roman opaque colored glasses, in Ceramics and Civilization, vol. VIII, The Prehistory of Glassmaking Technology, Ed. McGray, The Amer. Ceram. Soc. Westerville, 1998,121-144.

33. Tite M.S., Freestone I., Mason R.B., Archaeometry, 1998; 40: 241.

34. Tite M.S., Shortland A.J., Paynter S., Acc. Chem. Res. 2002; 35: 585.

35. Henderson J., Acc. Chem. Res. 2002; 35: 594.

36. Tite M.S., Shortland A.J., Archaeometry, 2003; 45: 285.

37. Paynter H.P., Tite M.S., The Evolution of glazing technologies, in The Ancient Near East and Egypt - The Social Contest of Technological Change, Ed A. Shortland, Oxbow, Oxford, 2001, 239-254.

38. Sharma S.K., Simmons B., Amer. Mineral. 1981; 66: 118.

39. T., Gugliemi J., Colomban Ph., Solid State Ionics 1994; 70/71: 109. 
40. Jambu M., Exploratory and multivariate data analysis, Academic Press, 1991, pp. 474.

41. Shaver J.M., Chemometics for Raman Spectroscopy, in Handbook of Raman Spectroscopy, Lewis I.R., Edwards H.G.M. (eds), Marcel Dekker: New York, 2001; 275.

42. Picon M. Le traitement des données d' analyses, PACT "Datation-caractérisation des céramiques anciennes », Hackens T, Schvoerer M. (eds), Strasbourg-Conseil de L'Europe, 1984; 10: 379.

43. Magetti M., Archaeometry 2005; 47: 389.

44. Baxter M. J., Archaeometry 1991; 33: 29.

45. Michels J. W., Journal of Archaeological Science 1982; 9: 113.

46. Brody R. H., Edwards H. G. M., Pollard A. M. Analytica Chimica Acta 2001; 427: 147.

47. De Benedetto G.E., Fabbri B., Gualtieri S., Sabbatini L., Zambonin P.G., J. Cutural Heritage 2005; 6: 205. 


\begin{tabular}{|c|c|c|c|c|c|c|c|c|c|c|c|c|c|}
\hline $\begin{array}{l}\text { Materials } \\
\text { [Reference] }\end{array}$ & label & $\mathrm{SiO}_{2}$ & $\mathrm{Al}_{2} \mathrm{O}_{3}$ & $\mathrm{Na}_{2} \mathrm{O}$ & $\mathrm{PbO}$ & $\mathrm{K}_{2} \mathrm{O}$ & $\mathrm{CaO}$ & $\mathrm{SnO}_{2}$ & $\mathrm{MgO}$ & $\mathrm{Fe}_{2} \mathrm{O}_{3}$ & $\mathrm{MnO}$ & $\mathrm{P}_{2} \mathrm{O}_{5}$ & $\mathrm{CuO}$ \\
\hline $\begin{array}{l}\text { Obsidian, Bingöl } \\
{[25]}\end{array}$ & BIN1 & 75.3 & 10.5 & 5.3 & n.d. & 4.2 & 0.1 & n.d. & 0.2 & n.d. & 0.08 & n.d. & n.d. \\
\hline $\begin{array}{l}\text { Obsidian, Göllü Dağ } \\
\text { [25] }\end{array}$ & 2609 & 78 & 12.3 & 3.9 & n.d. & 4.3 & 0.4 & n.d. & 0.1 & 0.9 & 0.07 & n.d. & n.d. \\
\hline Porcelain glazes [8] & NG31 & 70.07 & 14.3 & 1.56 & n.d. & 6.42 & 6.58 & n.d. & 0.91 & 0.13 & n.d. & n.d. & n.d. \\
\hline $20^{\text {th }} \mathrm{c}$ & NG6 & 63.16 & 17.87 & 1.37 & n.d. & 5.72 & 11.46 & n.d. & 0.19 & 0.19 & n.d. & n.d. & n.d. \\
\hline & NG33 & 73.87 & 14.31 & 1.16 & n.d. & 4.85 & 4.96 & n.d. & 0.69 & 0.14 & n.d. & n.d. & n.d. \\
\hline $\begin{array}{l}\text { B-containing glass } \\
{[22]}\end{array}$ & $532 \mathrm{~S} 00 \mathrm{~B}$ & 57.9 & n.d. & 17.7 & n.d. & n.d. & n.d. & n.d. & 2 & n.d. & n.d. & n.d. & 5.7 \\
\hline Vietnamese & CCLCC001 & 76 & 9.9 & 0.4 & n.d. & 2 & 6 & n.d. & 1.2 & n.d. & n.d. & n.d. & n.d. \\
\hline $\begin{array}{l}\text { Porcelain/Stoneware } \\
\text { glazes \& naste 19[] }\end{array}$ & ECLGOLD1 & 68 & 13 & 1.4 & n.d. & 3.2 & 10.6 & n.d. & 1.4 & n.d. & n.d. & n.d. & n.d. \\
\hline $\begin{array}{l}\text { glazes \& paste } \\
15^{\text {th }} \mathrm{c} \text {. }\end{array}$ & CCLCC002 & 28.3 & 5.4 & 0.0123 & 54 & 0.5 & n.d. & n.d. & 0.6 & 0.9 & n.d. & n.d. & 3.7 \\
\hline $\begin{array}{l}\text { English Soft-paste } \\
\text { glaze, } \\
19^{\text {th }} \text { c. }[24,26]\end{array}$ & EASSINF3 & 68 & 10 & 1.7 & 9 & 3.5 & 8 & n.d. & n.d. & n.d. & n.d. & n.d. & n.d. \\
\hline $\begin{array}{l}\text { Phoenician/Roman } \\
\text { bead glass [18] }\end{array}$ & vpc26 & 59.58 & 2.42 & 19.65 & 0.17 & 0.86 & 8.30 & n.d. & 1.08 & 1.32 & 0.27 & 0.10 & n.d. \\
\hline $\begin{array}{l}\text { Omeyadd glass, } 8^{\text {th }} \\
\text { c. }[24]\end{array}$ & TESS1 & 73 & 3.5 & 11 & n.d. & 1 & 9.2 & n.d. & n.d. & 0.6 & n.d. & n.d. & n.d. \\
\hline & ST1EMAILB & 63 & 10.5 & 22.5 & n.d. & n.d. & n.d. & n.d. & n.d. & n.d. & n.d. & n.d. & n.d. \\
\hline Saljukids glazes & ST2EMAILA & 67.5 & 2.1 & 3.6 & n.d. & n.d. & n.d. & n.d. & n.d. & n.d. & n.d. & n.d. & n.d. \\
\hline $\begin{array}{l}11-1 \\
5287^{-1}-1\end{array}$ & TTEAMAILB & 72.7 & 4.7 & 11.1 & n.d. & n.d. & n.d. & n.d. & n.d. & n.d. & n.d. & n.d. & n.d. \\
\hline & S3EMAIL & 55.8 & 13.4 & n.d. & 11.2 & n.d. & n.d. & n.d. & n.d. & n.d. & n.d. & n.d. & n.d. \\
\hline $\begin{array}{l}\text { Iznik glazes, } 16^{\text {th }} \mathrm{c} \text {. } \\
\text { [29] }\end{array}$ & EIZBROU3 & 46 & 0.4 & 10.2 & 29 & 0.9 & 0.8 & 5.6 & 0.2 & n.d. & n.d. & n.d. & n.d. \\
\hline Stained glass [27] & StChapvbleu1 & 53.4 & 1.7 & 1 & n.d. & 17.5 & 15 & n.d. & 5.5 & 0.67 & 6.7 & 4.5 & n.d. \\
\hline
\end{tabular}

Table 1 : Compositions (wt \%) of the selected materials. 


\begin{tabular}{|c|c|c|c|c|c|c|c|}
\hline \multirow{2}{*}{$\begin{array}{l}\text { Materials } \\
\frac{\mathrm{K}_{2} \mathrm{O}+\mathrm{CaO}+\mathrm{Al}_{2} \mathrm{O}_{3} "}{}\end{array}$} & \multirow[t]{2}{*}{ Labels } & \multirow{2}{*}{$\begin{array}{c}\mathrm{Ip} \\
<3.6>\end{array}$} & \multicolumn{5}{|c|}{$v \mathrm{Q}_{0} v \mathrm{Q}_{1} v \mathrm{Q}_{2} v \mathrm{Q}_{3} v \mathrm{Q}_{4} \mathrm{AQ}_{0} \mathrm{AQ}_{1} \mathrm{AQ}_{2} \mathrm{AQ}_{3} \mathrm{AQ}_{4} \mathrm{AQ}_{2} / \mathrm{AQ}_{3} \mathrm{AQ}_{2} / \mathrm{AQ} 1$} \\
\hline & & & & & & & \\
\hline Obsidian Göllü Dag [25] & 2609 & 3.7 & 101010641145 & 3.43 & 3.643 .3610 .88 & 1.08 & \\
\hline $18^{\text {th }} \mathrm{c}$. Porcelain glaze & buffon2 & 4.93 & 98410281130 & 2.92 & $\begin{array}{lll}1.64 & 2.47 & 9.84\end{array}$ & 0.66 & \\
\hline Modern Porcelain [8] & NG31 & 3.34 & 79794910391150 & 1.80 & $3.1612 .044 .92 \quad 0.00$ & 2.45 & 3.81 \\
\hline$"$ & NG6 & 2.38 & 78796210401131 & 2.83 & $\begin{array}{llll}7.13 & 10.98 & 8.65 & 0.00\end{array}$ & 1.27 & 1.54 \\
\hline$"$ & NG33 & 3.57 & 79895010441152 & 1.65 & $2.0413 .554 .60 \quad 0.00$ & 2.95 & 6.64 \\
\hline $2-" \mathrm{CaO} "$ & & $<1.7>$ & & & & & \\
\hline Modern B-glass [22] & $532 \mathrm{~S} 00 \mathrm{~B}$ & 1.79 & 7399089851056 & 2.22 & $4.8911 .0715 .02 \quad 0.00$ & 0.74 & 2.26 \\
\hline $\begin{array}{l}15^{\text {th }} \mathrm{c} . \text { Vietnamese } \\
\text { porcelain glaze }[19,20]\end{array}$ & CCLCC001 & 1.58 & 78992598310501140 & 0.94 & 6.7412 .6612 .715 .72 & 1.00 & 1.88 \\
\hline $\begin{array}{l}15^{\text {th }} \text { c. Vietnamese } \\
\text { celadon glaze }[19,20]\end{array}$ & ECLGOLD1 & 1.46 & 792960103510941160 & 1.90 & $13.7614 .275 .85 \quad 4.81$ & 2.44 & 1.04 \\
\hline $19^{\text {th }}$ c. soft-paste glaze [26] & EASSINF3 & 2.03 & 795952103111081163 & 2.52 & $7.0011 .663 .06 \quad 5.64$ & 3.81 & 1.67 \\
\hline Obsidian, Bingöl [25] & BIN1 & 1.59 & 98710601134 & 1.63 & 14.317 .4015 .19 & 1.93 & \\
\hline $3-" \mathrm{Na}_{2} \mathrm{O}+\mathrm{K}_{2} \mathrm{O}+\mathrm{CaO} "$ & & $<1.02>$ & & & & & \\
\hline $\begin{array}{l}\text { Phoenician/Roman } \\
\text { bead glass [18] }\end{array}$ & vpc17 & 1.2 & 780957104610931129 & 2.87 & 1.1713 .029 .6112 .73 & 1.35 & 11.13 \\
\hline " & vpc26 & 1.07 & 7808919369931087 & 1.55 & $\begin{array}{llll}3.13 & 4.07 & 7.69 & 38.50\end{array}$ & 0.53 & 1.30 \\
\hline $8^{\text {th }}$ c. Abbasid glass [24] & TESS1 & 0.97 & 79194799110241091 & 1.18 & $8.192 .06 \quad 3.6235 .56$ & 0.57 & 0.25 \\
\hline Modern stained glass [27] & AMvjaun 1 & 0.89 & 770950105111041158 & 2.88 & 7.7417 .8920 .093 .90 & 0.89 & 2.31 \\
\hline " & AMvvert1 & 0.95 & 792948104711001148 & 1.67 & 3.9615 .3517 .0112 .02 & 0.90 & 3.88 \\
\hline $4-" \mathrm{Na}_{2} \mathrm{O} "$ & & $<0.90>$ & & & & & \\
\hline $18^{\text {th }}$ c. Kutahya glaze [23] & $\mathrm{Ku} 2$ blanc & 0.83 & 78791398710801160 & 1.80 & $2.31 \quad 17.4128 .563 .78$ & 0.61 & 7.54 \\
\hline $\begin{array}{c}11^{\text {th }}-13^{\text {th }} \text { c. Seljukids glaze } \\
{[28,29]}\end{array}$ & ST1EMAILB & 0.8 & 78191398010691114 & 0.59 & 6.6921 .1316 .3510 .57 & 1.29 & 3.16 \\
\hline$"$ & ST2EMAILA & 1.13 & 790945100010831168 & 1.77 & 9.4411 .2127 .373 .08 & 0.41 & 1.19 \\
\hline$"$ & TTEAMAILB & 0.85 & 78692098310761156 & 1.33 & $4.60 \quad 19.0226 .202 .97$ & 0.73 & 4.13 \\
\hline $5-" \mathrm{Na}_{2} \mathrm{O}+\mathrm{PbO} "$ & & $<0.41>$ & & & & & \\
\hline $16^{\text {th }}$ c. Iznik glaze [29] & EIZB201 & 0.49 & 78393098010431122 & 2.02 & 11.0010 .5333 .5610 .00 & 0.31 & 0.96 \\
\hline Medieval Ifrikiya glaze [21] & DG44501 & 0.45 & 78395610391142 & 2.02 & $\begin{array}{lll}30.5829 .25 & 7.33 & 0.00\end{array}$ & 3.99 & 0.96 \\
\hline $16^{\text {th }}$ c. Iznik glaze [29] & EIZBROU3 & 0.31 & 78092097410361113 & 2.10 & 11.2815 .8135 .4811 .53 & 0.45 & 1.40 \\
\hline Medieval Ifrikiya glaze [21] & DG472002 & 0.4 & 77992397410301112 & 2.44 & 13.6915 .8526 .8512 .37 & 0.59 & 1.16 \\
\hline $6-" \mathrm{CaO}+\mathrm{K}_{2} \mathrm{O} "$ & & $<0.35>$ & & & & & \\
\hline Stained glass [27] & StChapvbleu1 & 0.38 & 773920100710931178 & 1.00 & 7.5017 .2228 .152 .31 & 0.61 & 2.30 \\
\hline$"$ & TRvjaune1 & 0.32 & 74787994410131086 & 1.39 & 5.7615 .4527 .4124 .88 & 0.56 & 2.68 \\
\hline $7-" \mathrm{PbO} "$ & & $<0.27>$ & & & & & \\
\hline Medieval Ifrikiya glaze [21] & DG5102 & 0.36 & 77490298510961144 & 1.32 & $10.3852 .702 .56 \quad 5.82$ & 20.59 & 5.08 \\
\hline $\begin{array}{c}11^{\text {th }}-13^{\text {th }} \text { c. Saljukids glaze } \\
{[28,29]}\end{array}$ & S3EMAIL & 0.48 & 78091997410291131 & 1.91 & 21.1318 .8415 .929 .72 & 1.18 & 0.89 \\
\hline $\begin{array}{l}15^{\text {th }} \mathrm{c} \text {. Vietnamese } \\
\text { porcelain glaze }[19,20]\end{array}$ & CCLCC002 & 0.36 & 75988895810171092 & 0.54 & 23.4134 .5014 .898 .13 & 2.32 & 1.47 \\
\hline $6^{\text {th }}-11^{\text {th }}$ c. Byzantin glaze & B6EMAILB & 0.11 & 7608829601093 & 0.23 & 14.1764 .6410 .000 .00 & 6.46 & 4.56 \\
\hline " & B1EMAILA & 0.06 & 85589695210141092 & 8.46 & 24.6139 .5915 .046 .84 & 2.63 & 1.61 \\
\hline
\end{tabular}

Table 2 : Main Raman parameters of selected materials; Ip, index of polymerisation, $v \mathrm{Q}_{\mathrm{n}}$, centre of gravity wavenumber $\left(\mathrm{cm}^{-1}\right)$ of the Si-O stretching $\mathrm{Q}_{\mathrm{n}}$ component, $\mathrm{AQ}_{\mathrm{n}}$, component area $(\%$ of all the peak area) and ratio. 


\section{FIGURE CAPTIONS}

Fig. 1 : a) Schematic diagram of the $\mathrm{SiO}_{4}$ polymerized network of a glassy silicate; isolated $\left(\mathrm{Q}_{0}\right)$, connected with one $\left(\mathrm{Q}_{1}\right)$, two $\left(\mathrm{Q}_{2}\right)$, three $\left(\mathrm{Q}_{3}\right)$ and four $\left(\mathrm{Q}_{4}\right)$ Si-O-Si bridge tetrahedra are indicated. b) example of glaze spectrum after baseline subtraction. Note, in the shown case (Medici porcelain [3,6]) additional narrow peaks due to $\alpha$-quartz and calcium phosphate crystalline phases are superimposed on the glaze Raman signature.

Fig. 2 : The polymerization index measured for a series of glazes and glasses of different origins and periods.

Fig. 3 : Polymerization index measured for a series of glazes and glasses of different origins and periods (see Fig.1); the wt \% flux oxide composition is indicated : $\mathbf{P b O}, \mathrm{Na}_{2} \mathrm{O}, \mathbf{K}_{\mathbf{2}} \mathbf{O}, \mathrm{CaO}$.

Fig. 4 : Representative Raman spectra for the 7 families identified : a) as-recorded spectra; b) baselines have been subtracted in order to only keep the " $\mathrm{SiO}_{4}$ " molecular signature (the contribution of the "Boson peak" is eliminated).

Fig. 5 : The Si-O stretching and bending $\mathrm{Q}_{\mathrm{n}}$ components have been fitted according to previously established methods $[1,7,8]$. See Fig. 4 caption for material assignment. Polymerisation Index and $\mathrm{Si}-\mathrm{O}$ envelope maximum wavenumbers are indicated

Fig. 6 : Plot of the polymerisation index as a function of the Qn wavenumber. Labels, see Fig.2. Dashed lines are guides for the eyes.

Fig. 7 : Plot of the compositional parameters for various glasses and glazes of different periods (after [17-19,29-37] : a) $\left[0.5 \mathrm{Al}_{2} \mathrm{O}_{3} / \mathrm{SiO}_{2}\right]$ mole ratio and b) $\left[0.5 \mathrm{Na}_{2} \mathrm{O}+0.5 \mathrm{~K}_{2} \mathrm{O}+\mathrm{CaO}\right] /\left[0.5 \mathrm{Al}_{2} \mathrm{O}_{3}\right.$ $\left./ \mathrm{SiO}_{2}\right]$ mole ratio.

Fig. 8 : Example of Raman signatures (families 3 and 7).

Fig. 9 : Plots of the polymerisation index as a function of the main Si-O stretching component wavenumber (a) and the $\mathrm{Q}_{2} / \mathrm{Q}_{1}$ area ratio (b).

Fig. 10 : Hierarchical cluster built with 10 parameters, namely the index of polymerisation (Ip), the wavenumber of the Si-O peak maxima, the Qn wavenumbers and peak areas. Number correspond to families of figures 5 and 9. Sample label: Family number according Figs $4 \& 5$ - material (Por: modern porcelain; Iz : Iznik; G: glass; Ku: Kütahya; SG: stained glass; Stn : stoneware; GOm: Omeyyad glass; Sal: Saljukids; By: Byzantine; If: Ifriqiya) - colour (b: blue; g: green; y: yellow; go: gold; bk: black E: enamel/glaze). Additional museum reference number is indicated for artefacts of the Musée national de Céramique, Sèvres, France. 
Fig. 11 : Projection on the two first factors extracted from Principal Component Analysis of the 10 parameters used for the 30 reference spectra.

Fig. 12 : (a) Bi-plot of the polymerisation index $\left(I_{p}\right)$ as a function of the Si-O stretching wavenumber maximum (see Fig. 9a) and (b) hierarchical cluster (calculated for the 10 parameters) for the series of Iznik and Kütahya fritware glazes. Sample label : Curator' assignment (Iz, Iznik; $\mathrm{Ku}, \mathrm{Kütahya),} \mathrm{colour} \mathrm{(} \mathrm{b:} \mathrm{blue,} \mathrm{r}$ : red, ...), artefact record number, additional information.

a)
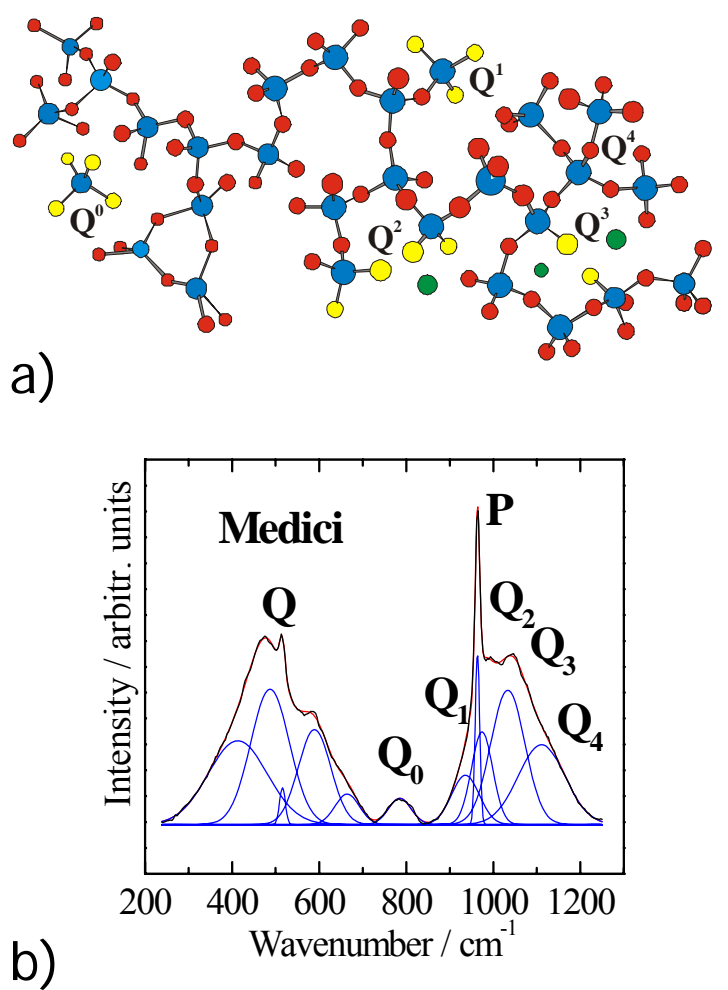

Fig. 1 : a) Schematic diagram of the $\mathrm{SiO}_{4}$ polymerized network of a glassy silicate; isolated $\left(\mathrm{Q}_{0}\right)$, connected with one $\left(\mathrm{Q}_{1}\right)$, two $\left(\mathrm{Q}_{2}\right)$, three $\left(\mathrm{Q}_{3}\right)$ and four $\left(\mathrm{Q}_{4}\right)$ Si-O-Si bridge tetrahedra are indicated. b) example of glaze spectrum after baseline subtraction. Note, in the shown case (Medici porcelain $[3,6]$ ) additional narrow peaks due to $\alpha$-quartz and calcium phosphate crystalline phases are superimposed on the glaze Raman signature. 


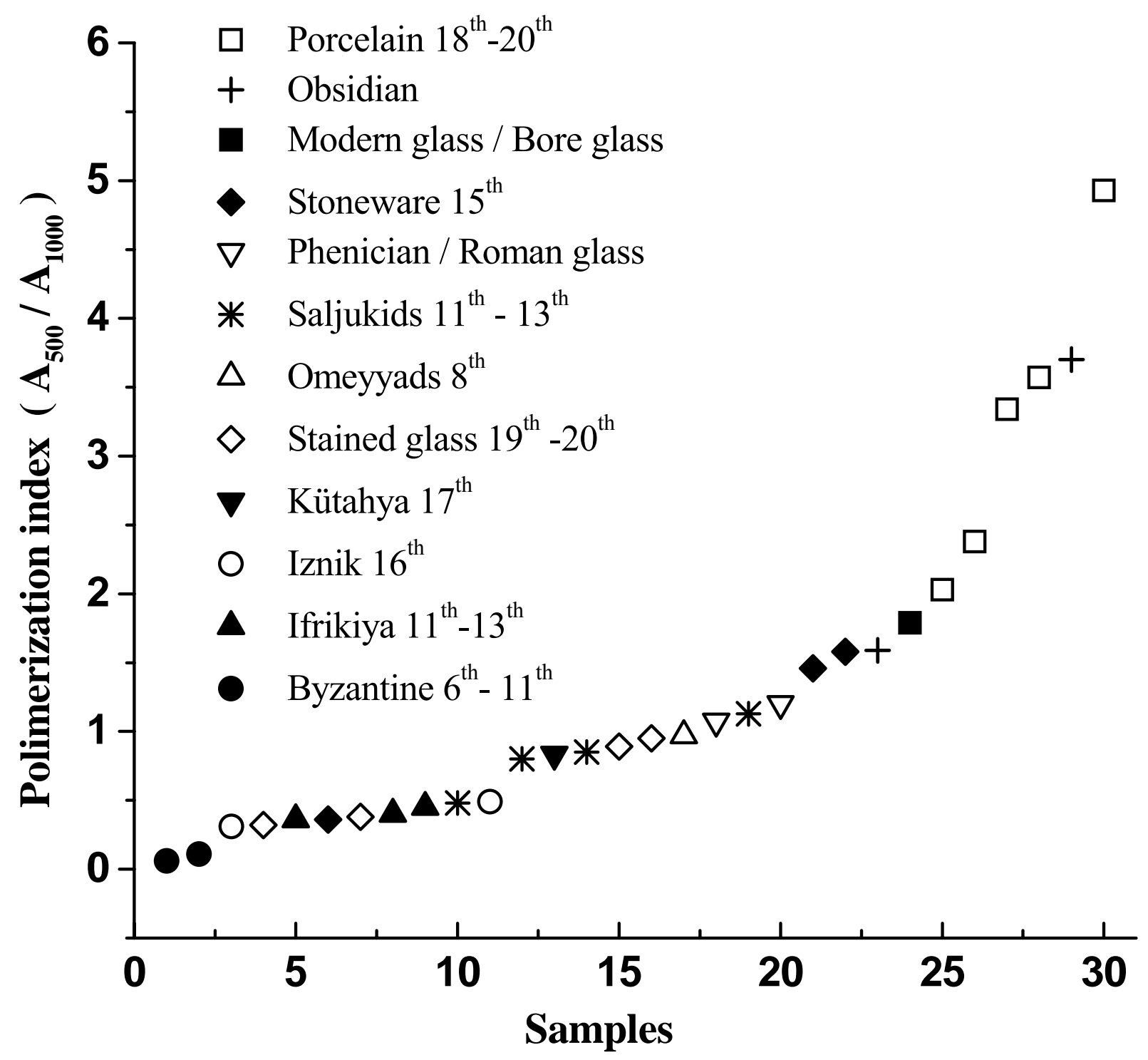

Fig. 2 : The polymerization index measured for a series of glazes and glasses of different origins and periods. 


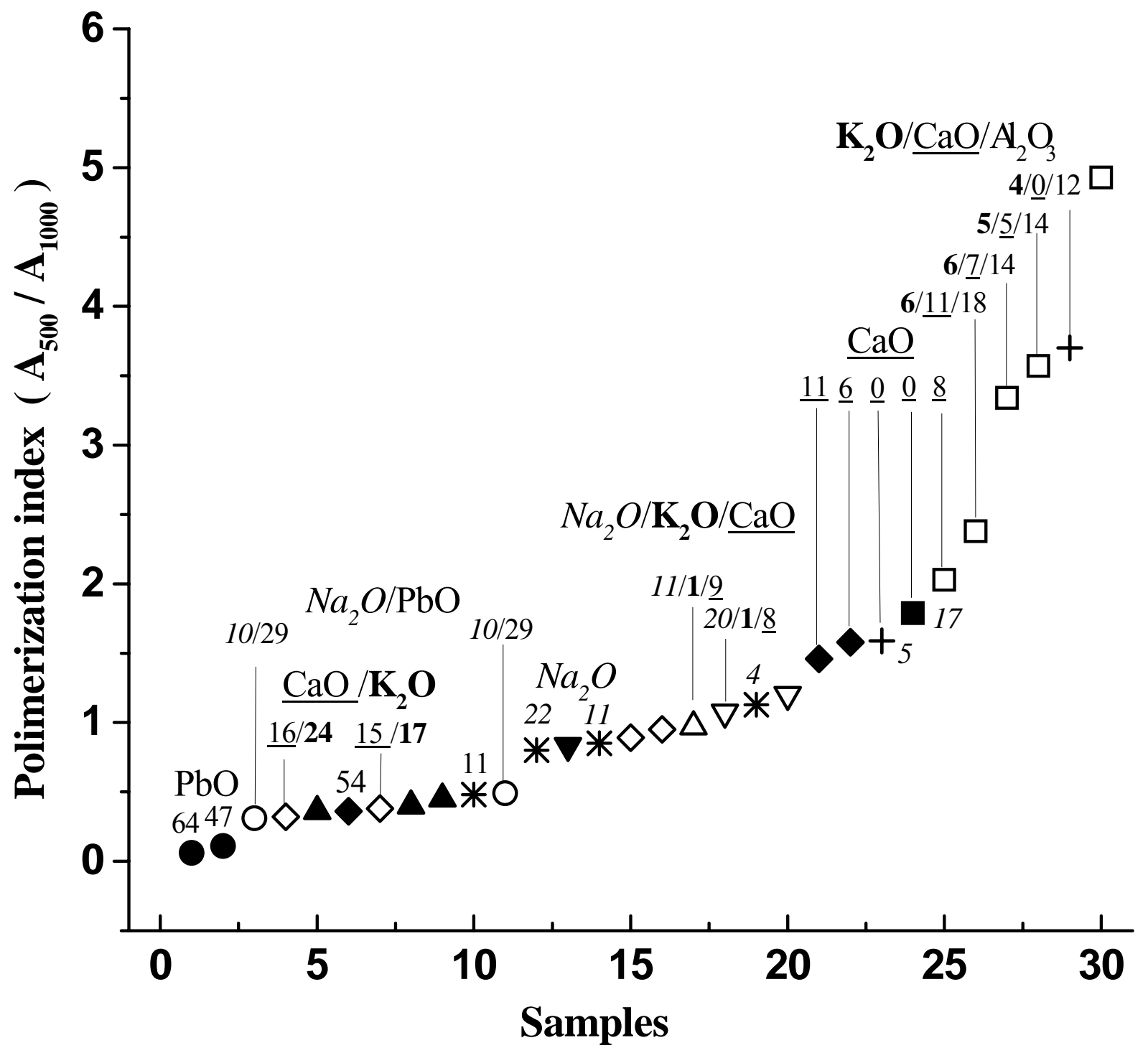

Fig. 3 : Polymerization index measured for a series of glazes and glasses of different origins and periods (see Fig. 1) ; the wt \% flux oxide composition is indicated: $\mathbf{P b O}, \mathrm{Na}_{2} \mathrm{O}, \mathbf{K}_{2} \mathbf{O}, \mathrm{CaO}$. 


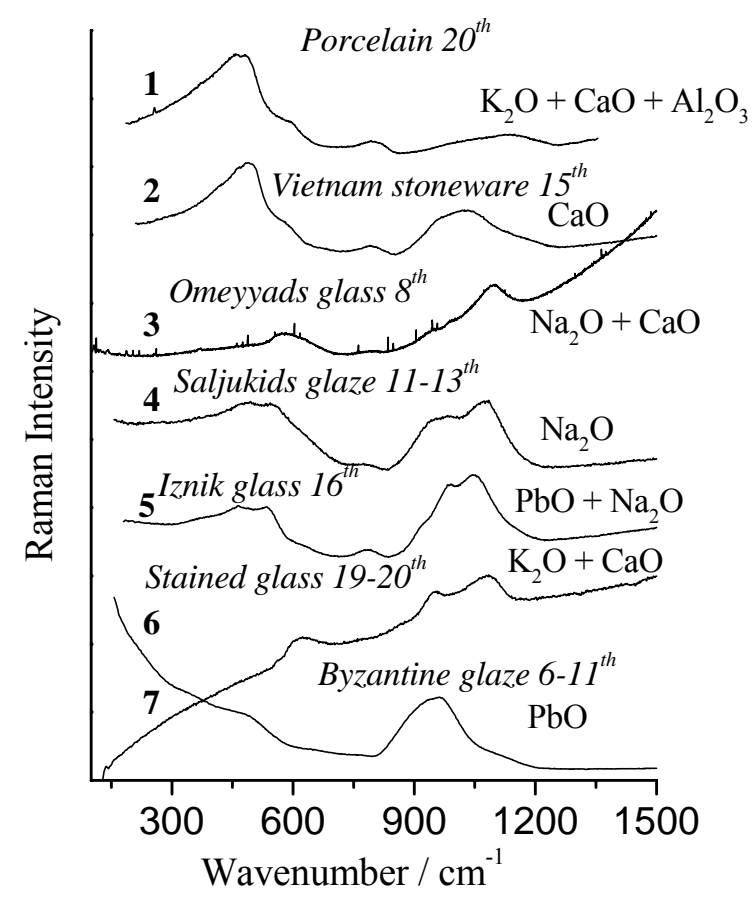

a) b)

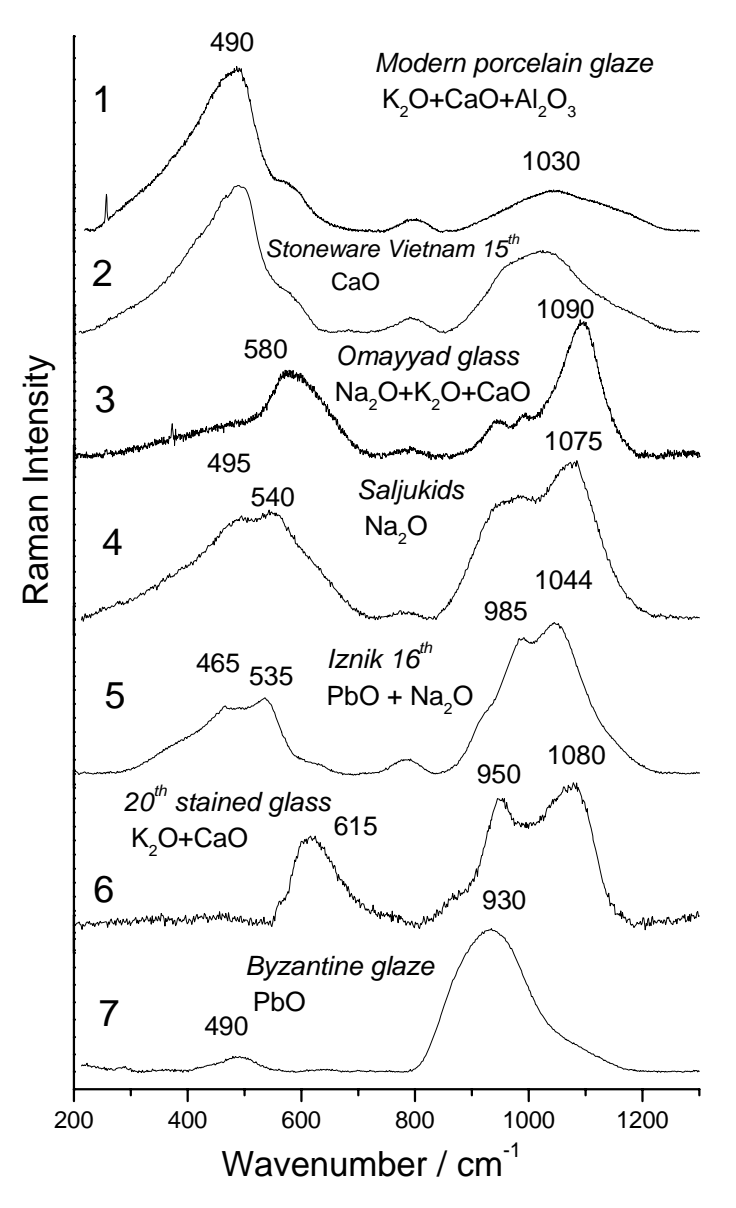

Fig. 4 : Representative Raman spectra for the 7 families identified : a) as-recorded spectra; b) baselines have been subtracted in order to only keep the "SiO $4 "$ molecular signature (the contribution of the "Boson peak" is eliminated). 


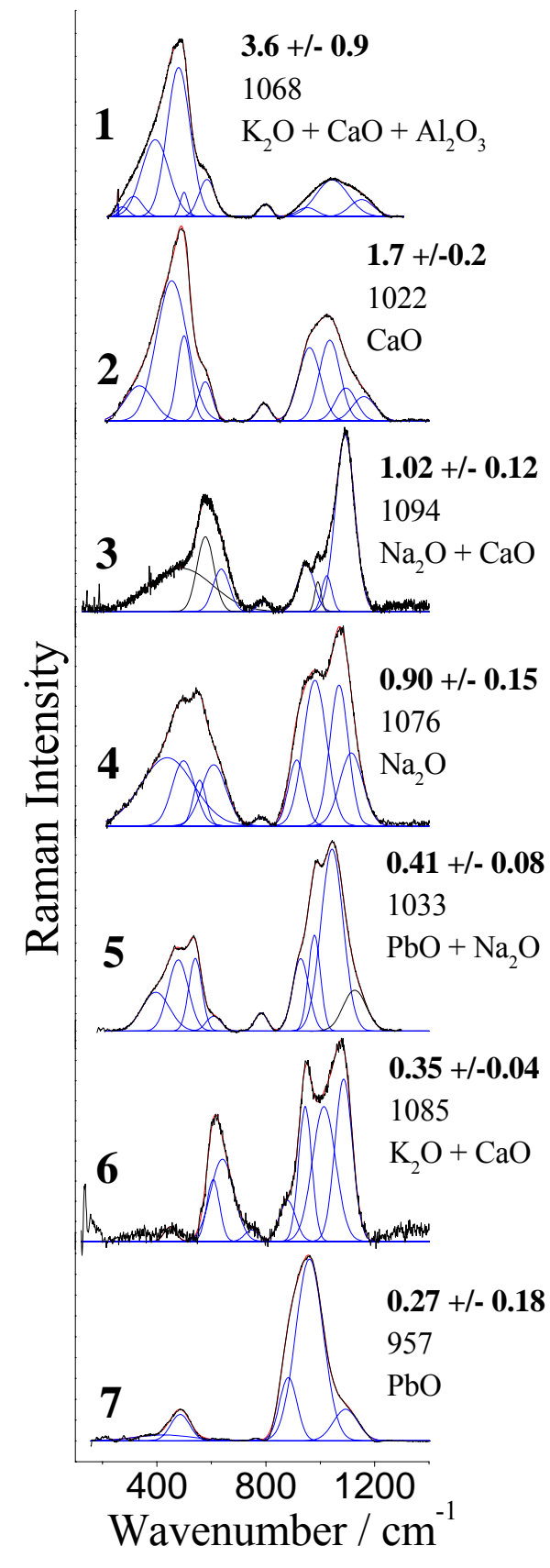

Fig. 5 : The Si-O stretching and bending $\mathrm{Q}_{\mathrm{n}}$ components have been fitted according to previously established methods $[1,7,8]$. See Fig. 4 caption for material assignment. Polymerisation Index and $\mathrm{Si}-\mathrm{O}$ envelope maximum wavenumbers are indicated 

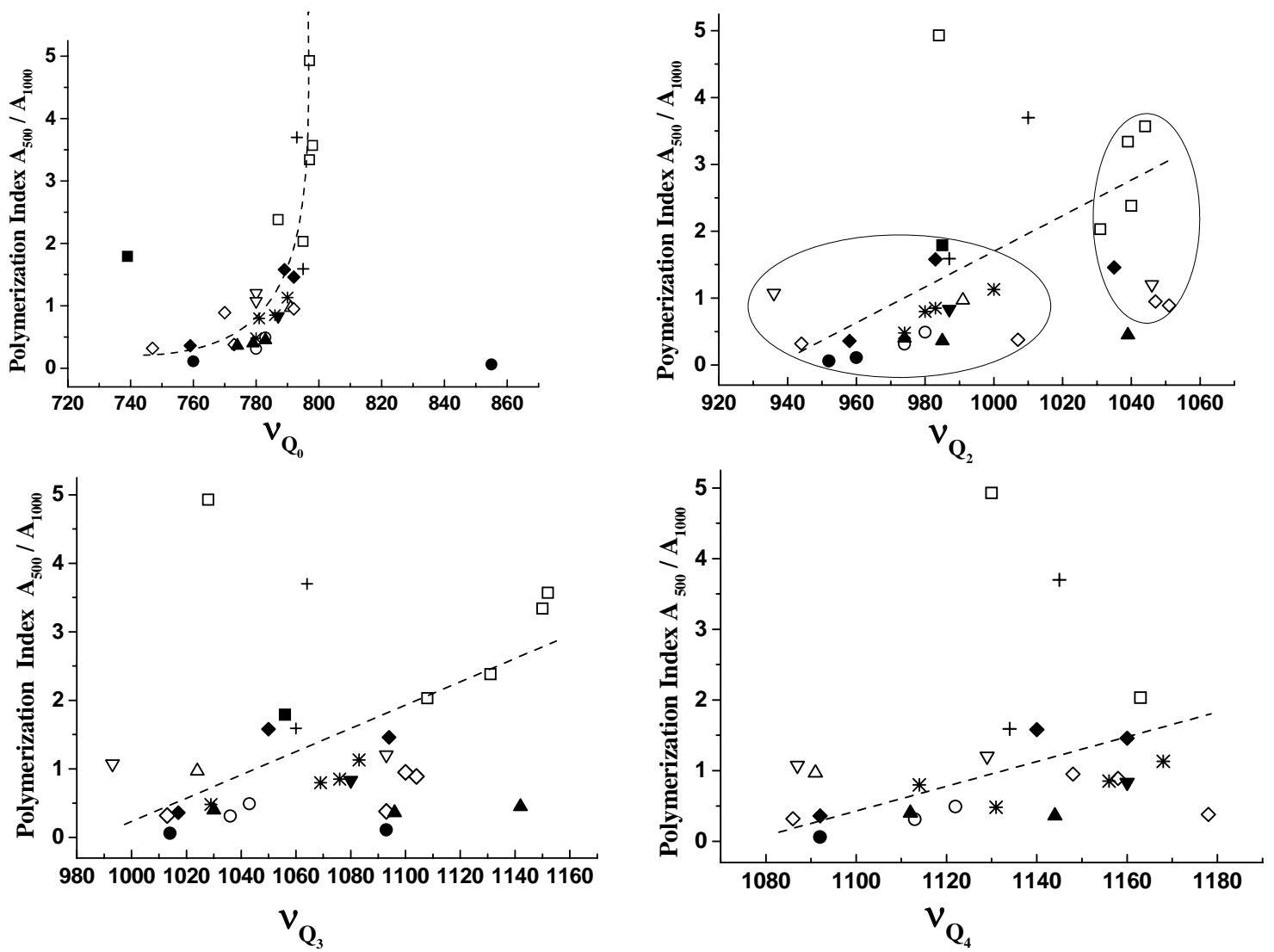

Fig. 6 : Plot of the polymerisation index as a function of the Qn wavenumber. Labels, see Fig.2. Dashed lines are guides for the eyes. 

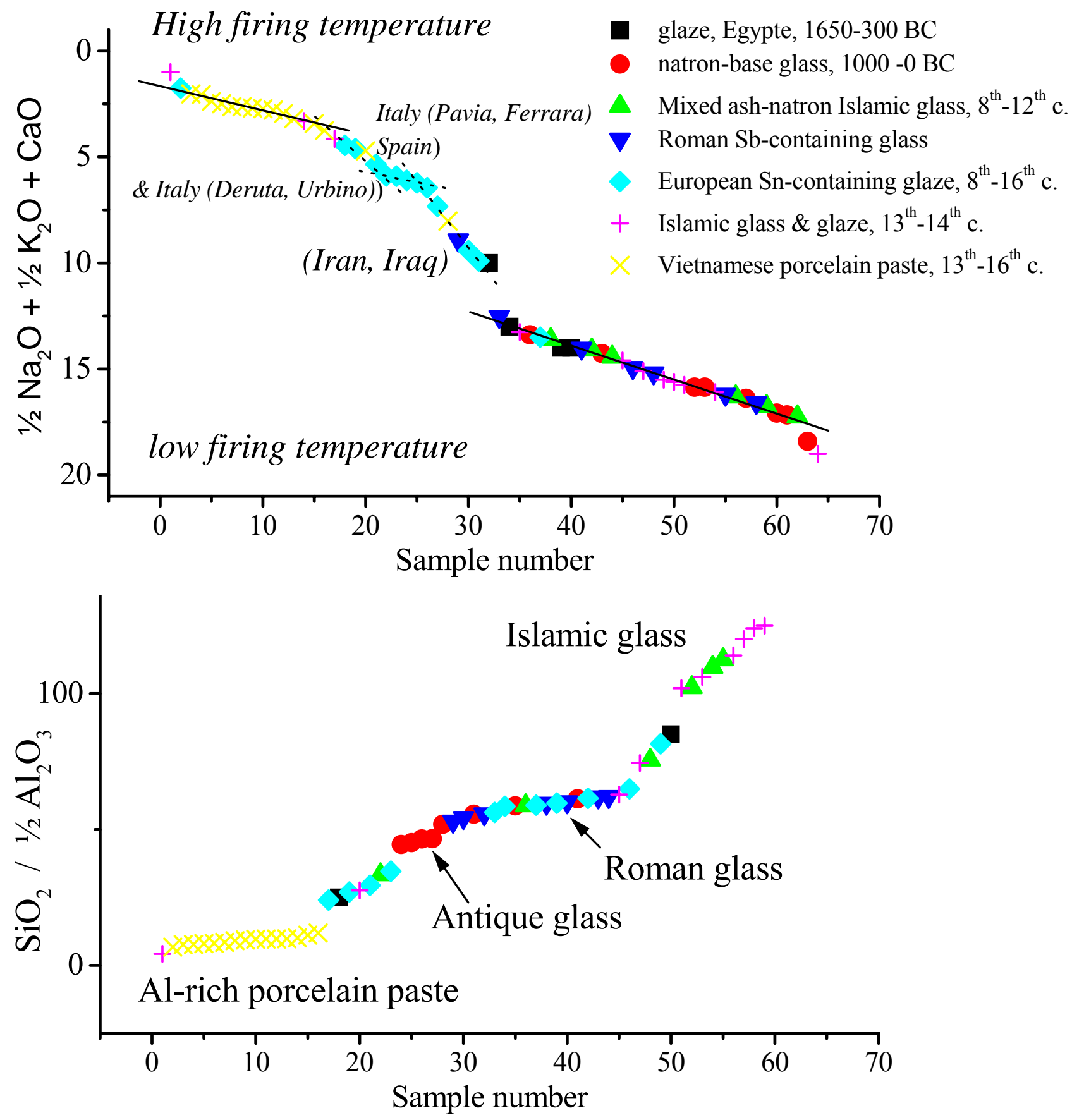

Fig. 7 : Plot of the compositional parameters for various glasses and glazes of different periods (after [17-19,29-37] : a) $\left[0.5 \mathrm{Al}_{2} \mathrm{O}_{3} / \mathrm{SiO}_{2}\right]$ mole ratio and b) $\left[0.5 \mathrm{Na}_{2} \mathrm{O}+0.5 \mathrm{~K}_{2} \mathrm{O}+\mathrm{CaO}\right] /\left[0.5 \mathrm{Al}_{2} \mathrm{O}_{3}\right.$ $\left./ \mathrm{SiO}_{2}\right]$ mole ratio. 

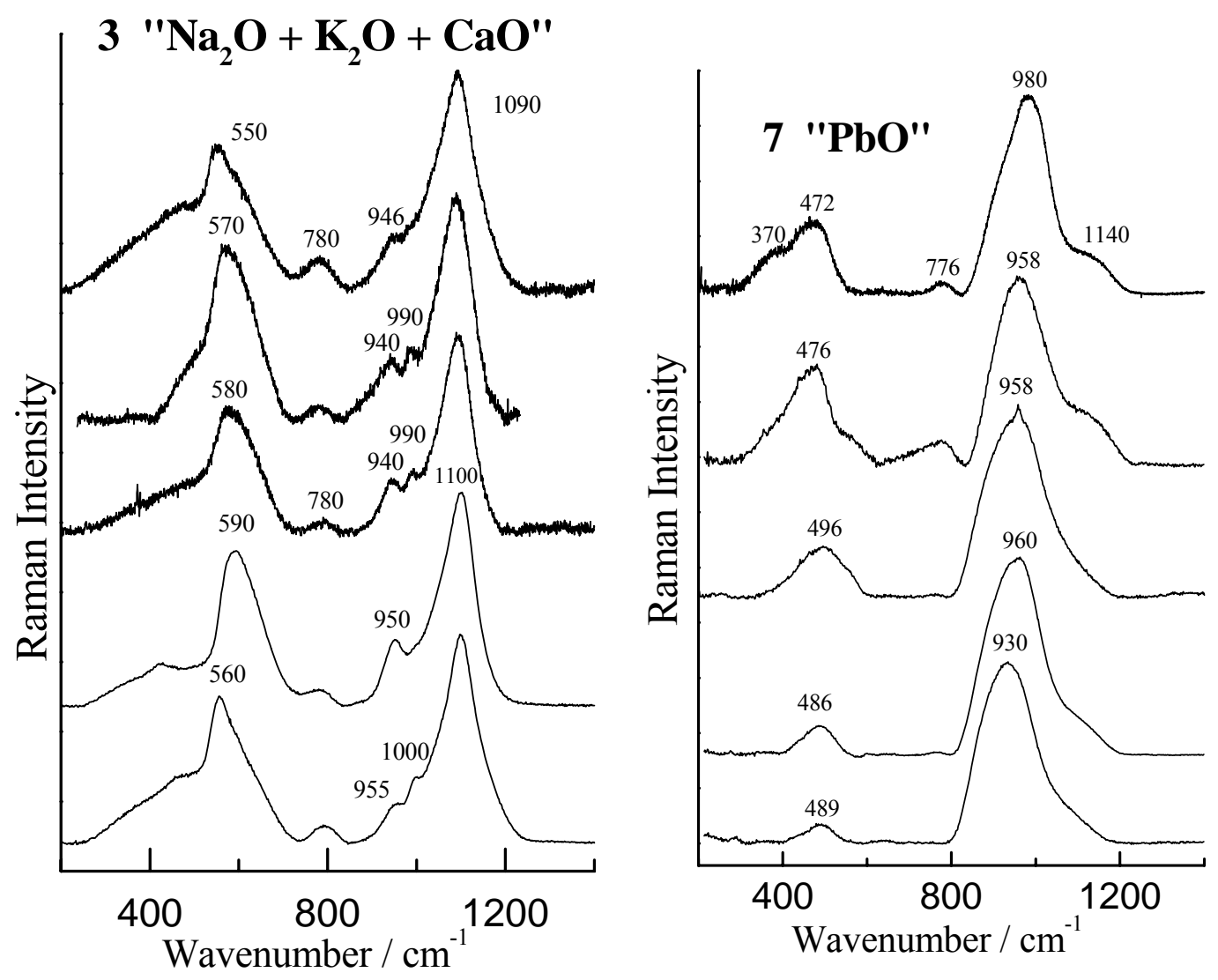

Fig. 8 : Example of Raman signatures (families 3 and 7). 
a)

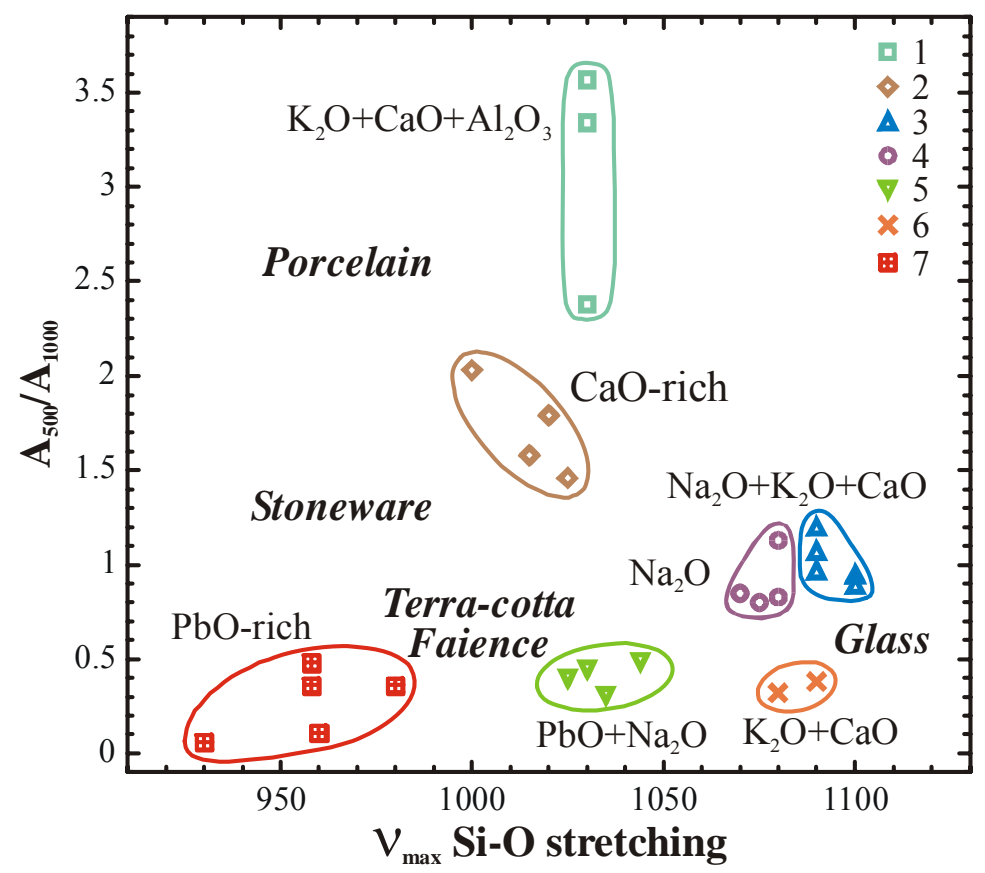

b)

+ Obsidian

$\square \quad$ Porcelain 18-20 ${ }^{\text {th }}$

- modern B:glass

- Vietnam stoneware glaze $15^{\text {th }}$

$\times$ Bone China glaze

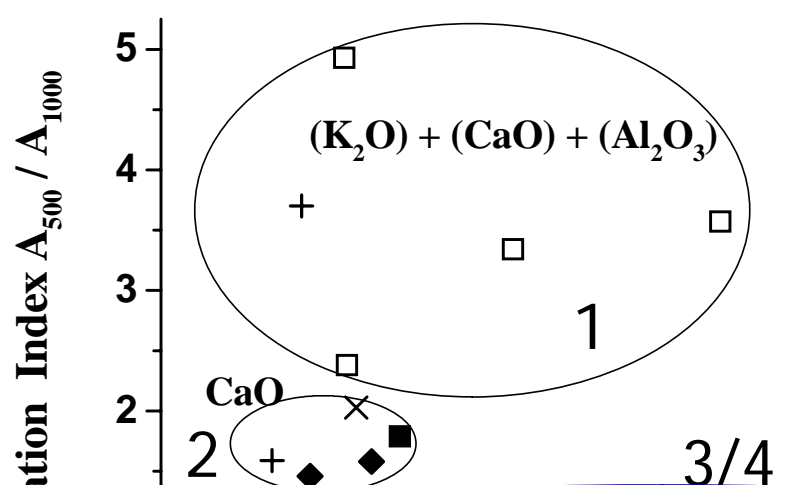

$\nabla$ Phoenician/Roman glass

$\triangle$ Omayyad glass $8^{\text {th }}$

$\diamond \quad$ Stained glass

V Kütahya glaze $18^{\text {th }}$

* Saljukids glaze $11-13^{\text {th }}$

Iznik glaze $16^{\text {th }}$

$\Delta$ Ifrikiya glaze $11-13^{\text {th }}$

- Byzantine glaze $6-11^{\text {th }}$

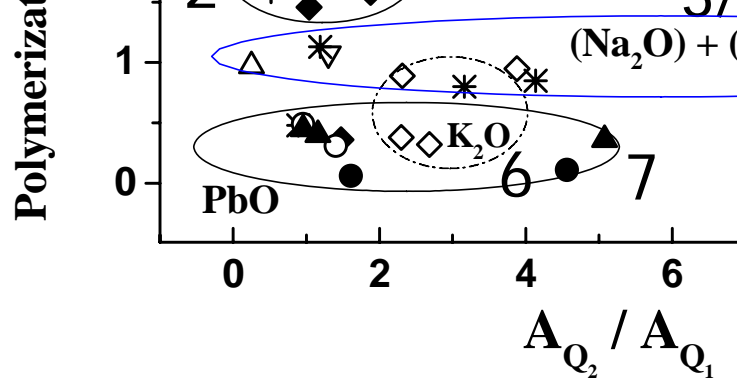

Fig. 9 : Plots of the polymerisation index as a function of the main Si-O stretching component wavenumber (a) and the $\mathrm{Q}_{2} / \mathrm{Q}_{1}$ area ratio (b). 


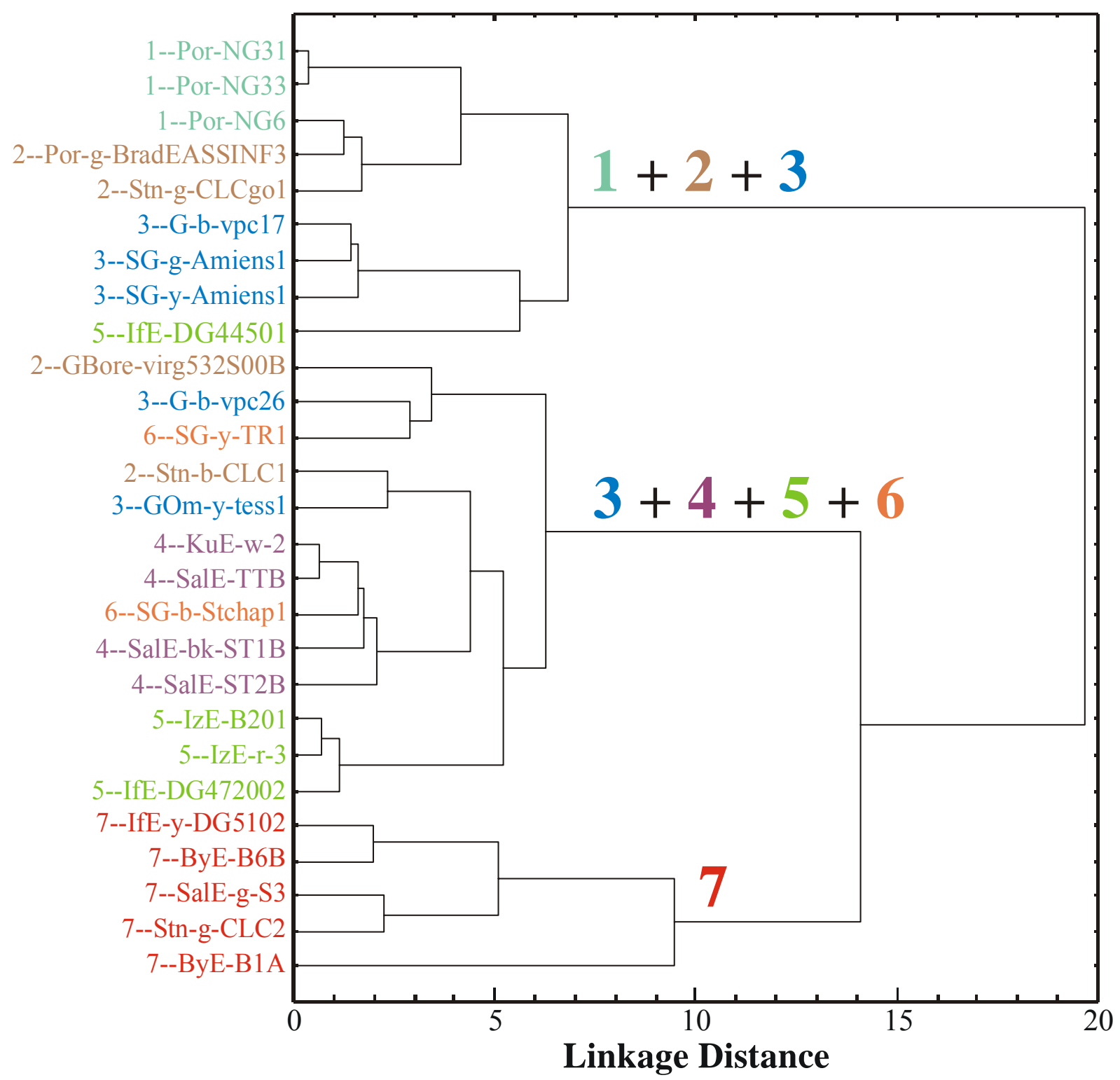

Fig. 10 : Hierarchical cluster built with 10 parameters, namely the index of polymerisation (Ip), the wavenumber of the Si-O peak maxima, the Qn wavenumbers and peak areas. Number correspond to families of figures 5 and 9. Sample label: Family number according Figs $4 \& 5$ - material (Por: modern porcelain; Iz : Iznik; G: glass; Ku: Kütahya; SG: stained glass; Stn : stoneware; GOm: Omeyyad glass; Sal: Saljukids; By: Byzantine; If: Ifriqiya) - colour (b: blue; g: green; y: yellow; go: gold; bk: black E: enamel/glaze). Additional museum reference number is indicated for artefacts of the Musée national de Céramique, Sèvres, France. 


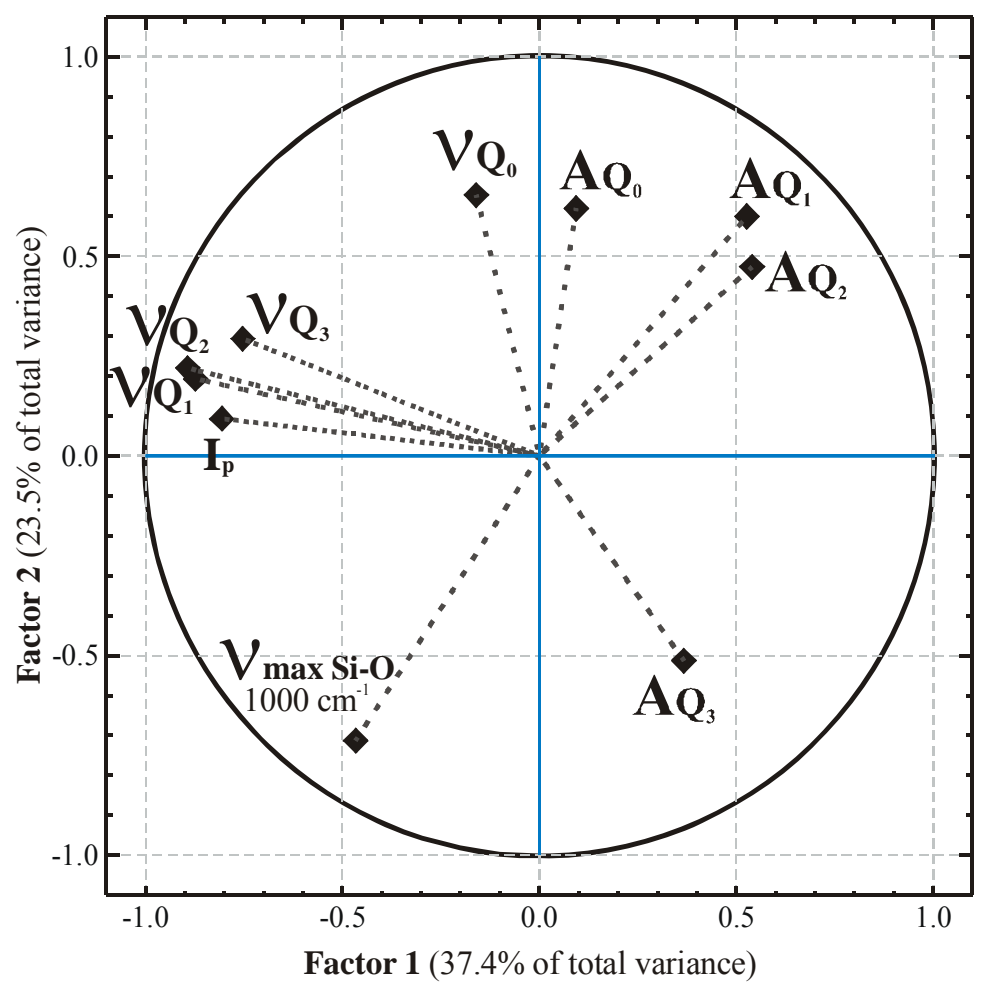

Fig. 11 : Projection on the two first factors extracted from Principal Component Analysis of the 10 parameters used for 30 reference spectra. 


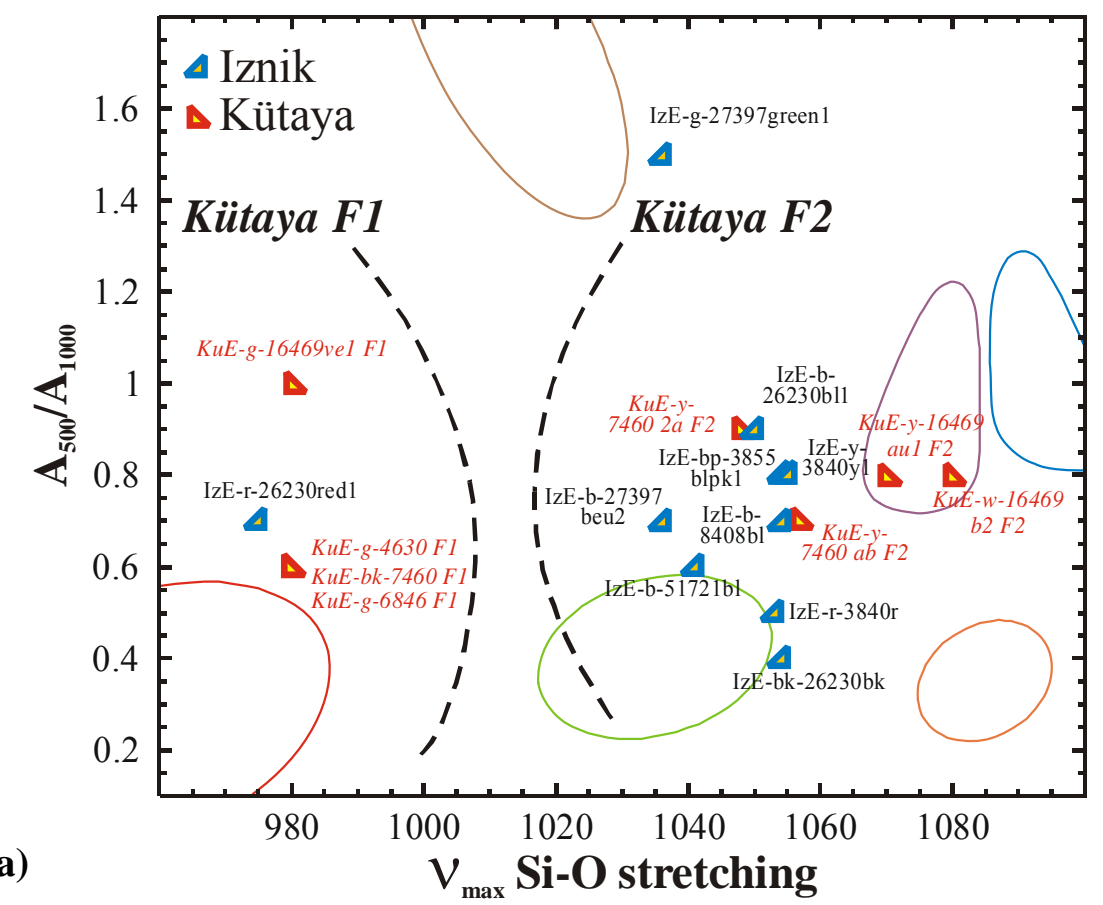

a) $V_{\text {max }}$ Si-O stretching

b)

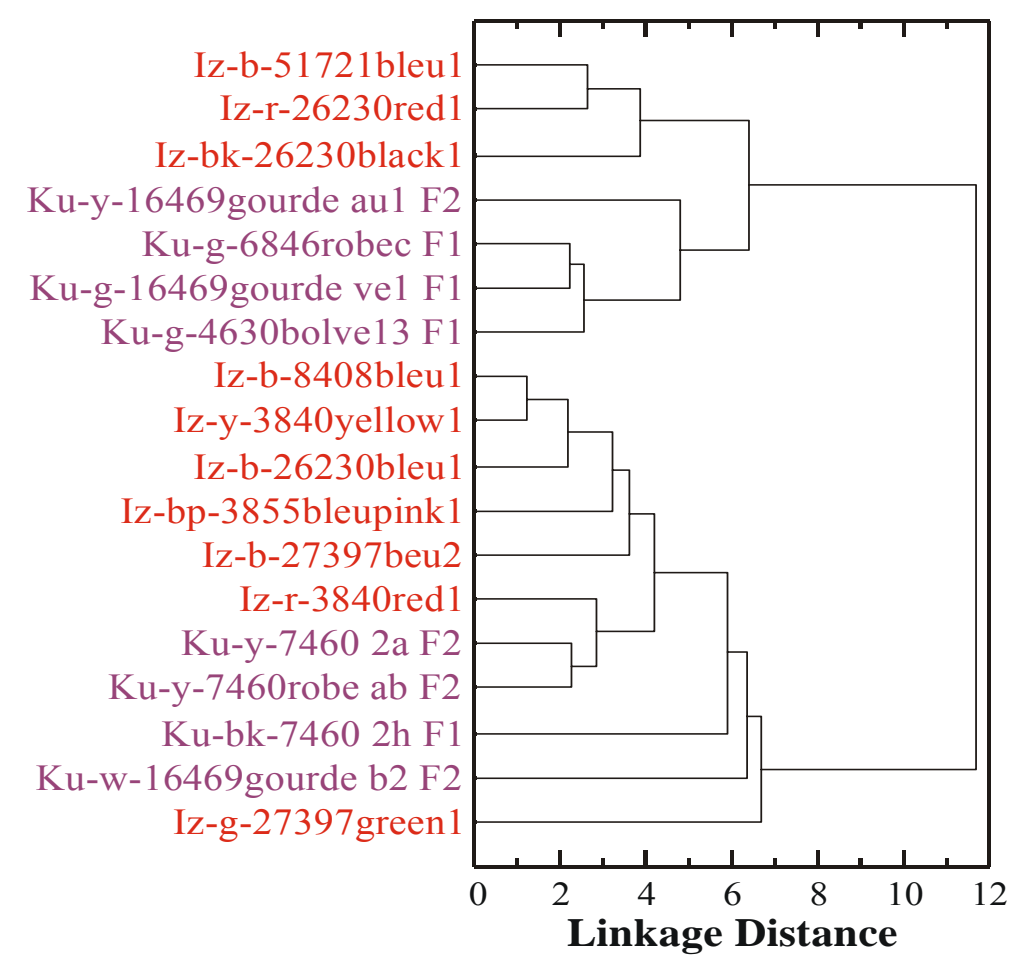

Fig. 12 : (a) Bi-plot of the polymerisation index $\left(\mathrm{I}_{\mathrm{p}}\right)$ as a function of the Si-O stretching wavenumber maximum (see Fig. 9a)) and (b) hierarchical cluster (calculated for the 10 parameters) for the series of Iznik and Kütahya fritware glazes. Sample label : Curator' assignment (Iz, Iznik; $\mathrm{Ku}$, Kütahya), colour ( b: blue, $\mathrm{r}$ : red, ...), artefact record number, additional information. 